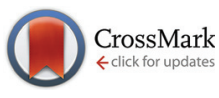

Cite this: Polym. Chem., 2017, 8, 220

\title{
How to manipulate the upper critical solution temperature (UCST)?
}

\author{
Jukka Niskanen and Heikki Tenhu*
}

In this mini-review, we discuss multi-stimuli-responsive polymers, which exhibit upper critical solution temperature (UCST) behavior mainly in aqueous solutions. Firstly, we discuss both the lower and upper critical solution temperature behavior of thermoresponsive polymers, to understand the differences between the two. This will be followed by examples of polymers that undergo a UCST phase transition. Secondly, we show how the solution properties of multi stimuli-responsive polymers can be influenced by several factors in addition to temperature, such as counter ions, electricity, light, or $\mathrm{pH}$. Common to all stimuli are their capabilities to induce changes in the conformations and interactions of the polymers. With UCST polymers, the thermoresponsiveness is predominantly dependent upon the presence of strong supramolecular interactions between the polymer side groups. These are known to be affected by the molecular weight of the polymer, the solution concentration, and the presence of salts. With all these different ways to affect the cloud point of the polymers, we have systems that are readily tunable to many applications.

Received 13th September 2016 Accepted 21st October 2016

DOI: $10.1039 / c 6 p y 01612 j$

www.rsc.org/polymers stimuli, such as a change in the temperature, $\mathrm{pH}$, or irradiation with light. Materials produced from stimuli-responsive polymers range from membranes and films to micelles and polymer brushes. ${ }^{1}$ These materials provide a promising array of materials for controlled and targeted drug delivery, which would be especially important in delivering drugs with severe side effects, as often is the case with cancer treatments.

Laboratory of Polymer Chemistry, Department of Chemistry, University of Helsinki, P.O. Box 55, 00014 Helsinki, Finland. E-mail: heikki.tenhu@helsinki.fi

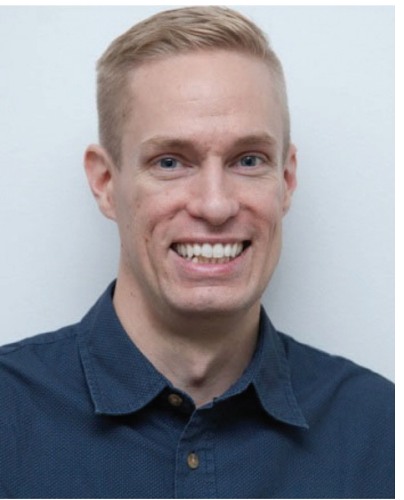

Jukka Niskanen.
Jukka Niskanen received his M.Sc in Chemistry (2008) and Ph.D. in polymer chemistry (2013) from the University of Helsinki, Finland. After his defence, he joined as a post-doc at the University of Montreal, Canada, supervised by Professor F. M. Winnik. Currently, he is working as an Academy of Finland post-doctoral researcher at the University of Helsinki, with Professor H. Tenhu. In this position, he has also been a visiting researcher at the University of Montreal and the National Institute for Materials Science (NIMS), WPI International Center for Materials Nanoarchitectonics (MANA), Japan. His current research interests are bioconjugates of polymeric zwitterions or boron nitride nanomaterials.

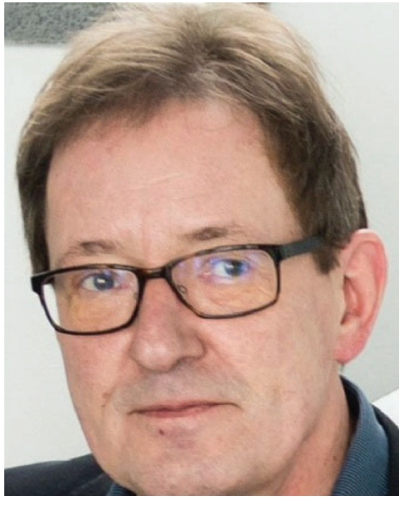

Heikki Tenhu.
Heikki Tenhu is a Professor of polymer chemistry at the University of Helsinki, since 1992. His research interests include synthesis and characterization of amphiphilic polymers, thermally responsive polymers, polyelectrolytes and polyelectrolyte complexes. Recently, much effort has been invested on hybrid nanomaterials. An important part of the research is characterization of self-assembling systems in aqueous solutions by scattering, spectroscopic and rheological methods. 
Other inspiring areas for applications are in the field of sensors or even actuators. ${ }^{1}$

Thermoresponsive polymers comprise the bulk of the stimuli-responsive polymers studied. Two very well-known examples of thermoresponsive polymers are polystyrene in cyclohexane and poly( $N$-isopropyl acrylamide) (PNIPAM) in water. Both undergo a change in their solubility with increasing the temperature of the solution. ${ }^{2,3}$ Polystyrene will dissolve in cyclohexane, in an upper critical solution temperature (UCST) type process. PNIPAM, on the other hand, will precipitate out from the solution in a lower critical solution temperature (LCST) process. However, it should be noted that both the UCST and LCST are single distinct points in a phase diagram, depicting the solution behavior of the polymer as a function of temperature versus the polymer concentration. In the diagram, the minimum or the maximum point of the solubility curves are the respective LCST and UCST points. ${ }^{2,4,5}$ Any other point along the respective curve is referred to as a cloud point $\left(T_{\mathrm{cp}}\right)$ or a demixing $\left(T_{\text {dem }}\right)$ point, depending on the method (turbidimetric or calorimetric, respectively) used for detection (Fig. 1). The solvent plays a key role in the solution behavior of polymers, as some thermoresponsive polymers can exhibit LCST behavior in one solvent and UCST in another. For example, PNIPAM displays UCST behavior in water/alcohol binary solvents. ${ }^{6}$

The temperature induced phase transition may go hand in hand with other stimuli, such as a change in the $\mathrm{pH}$ of the solution, as is the case with poly(dimethylaminoethyl methacrylate) (PDMAEMA) and polymers with similar structures. For these polymers, the phase transition is greatly affected by the charge of the polymer, i.e. the $\mathrm{pH}$ of the solution. ${ }^{7-9}$

There are numerous studies on the thermal response of LCST polymers, however, there are far less conducted on polymers expressing the UCST behavior. ${ }^{2,5,6}$ UCST polymers were recently discussed in a review by Seuring et al. together with

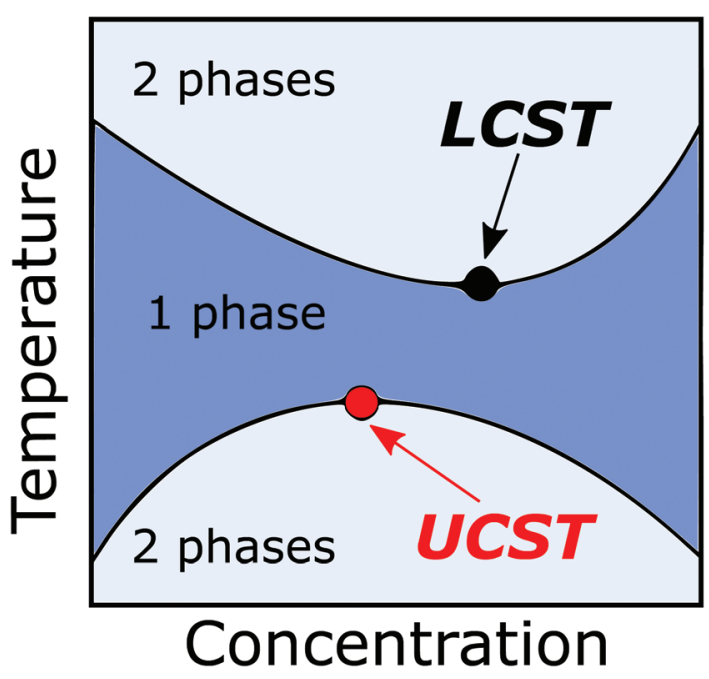

Fig. 1 A phase diagram showing the UCST (red) and LCST (black) points for a thermoresponsive polymer. an extensive discussion about the thermodynamics of the phenomenon. ${ }^{5}$ Changing the solvent quality or polarity can induce a UCST phase transition for several polymers. This aspect will only be briefly discussed in this review, as it was recently discussed in a review by Zhang et al. ${ }^{6}$ We focus on the stimuli that change the properties of polymers in solution either by electrochemical reactions, light-induced photoisomerization, bridging bonds via counterions, increasing the hydrophobicity of the polymers by complexation with hydrophobic counterions, or affecting the hydrogen bonding by changing the $\mathrm{pH}$ of the solution. All of these are dynamic effects; that is they are affected by several factors, including the temperature, concentration, molecular weight of the polymers, and the nature of the solvent. In this review, the focus will be on systems that show multi stimuli-responsive behavior in aqueous solutions, with only a few examples of systems in alcohols.

\section{Upper and lower critical solution temperature}

Let us first briefly consider polymers in aqueous solutions. Water is a structured solvent, as the molecules arrange themselves due to hydrogen bonding. Polar groups of the dissolved polymers affect the structure of the water, whereas charge neutral zwitterionic polymers have little effect. Hydrophobic groups, on the other hand, are contained in a cage of water molecules. The larger or more hydrophobic the groups are, the more easily the cage is broken and the polymer precipitates. The structure of water is suggested to be different in dilute and semidilute polymer solutions. Ultimately, all of these observations tell us about the interactions between the solubilized polymer and water. The addition of alcohols in water rearranges the structure of water and clusters formed. Increasing the fraction of alcohol results in smaller and smaller clusters of water. In binary alcohol-water mixtures either co-solvency or co-non-solvency may take place. In the case of co-solvency the polymers are solubilized via an alcohol layer around the hydrophobic parts of the polymer and these alcohol molecules can, in turn, participate in hydrogen bonding with the surrounding water. Co-non-solvency is observed when the polymer preferably takes part in hydrogen bonding with either water or alcohol and thus, the compatibilizing layer around the polymer will be lost. ${ }^{6,10,11}$

In order to understand how the UCST behavior can be tuned to specific applications, we need to examine the mechanisms of dissolution, and how UCST systems are different from LCST systems. In aqueous solutions, polymers are solubilized mainly via dipole-dipole interactions and hydrogen bonding between the polar groups present in the polymer. The nonpolar parts of the polymers are surrounded by a cage of water molecules. The interactions between the nonpolar groups and water are much weaker than the hydrogen bonds between water molecules. Thus the water molecules prefer to bond with each other, resulting in a cage of organized water 
<smiles>CC(C)NC(=O)C(CC(C)(C)C)C(C)(C)CC(C(=O)NCC(N)=O)C(C)(C)C</smiles>

Fig. 2 The structures of PNIPAM (left) and PNAGA (right).

molecules bound to the polymers. ${ }^{2,5}$ To understand the origins of the UCST we will first briefly examine the solution properties of poly( $N$-acryloyl glycinamide) (PNAGA, Fig. 2), a non-ionic UCST polymer. For comparison, we will also briefly discuss the solution behavior of PNIPAM (Fig. 2).

Strong supramolecular interactions govern the UCST behavior of polymers in water. These interactions can be either hydrogen bonds, as in the case of PNAGA, or electrostatic bonds occurring in and between zwitterionic polymers (Scheme 1). PNAGA is a non-ionic polymer that exhibits UCST behavior in water. Seuring et al. have shown that the thermoresponsiveness of PNAGA is due to the hydrogen bonding between the polymer side groups. They found that the cloud point of PNAGA is shifted to lower temperatures, eventually disappearing completely, by adding increasing amounts of sodium thiocyanate, which disrupts hydrogen bonds. ${ }^{12-14}$

Upon dissolution of PNAGA in water, the hydrogen bonds between the carbonyl and amine groups are broken in an endothermic process and replaced by hydrogen bonds with water in an exothermic process. Thus, the overall enthalpy of the dissolution process is low and ultrasensitive calorimeters are needed to measure it. For comparison, the enthalpy of the phase transition of PNAGA is reported to be $90 \mathrm{~J} \mathrm{~mol}^{-1}(0.7$ $\left.\mathrm{J} \mathrm{g}^{-1}\right),{ }^{13}$ whereas for PNIPAM it is $4-6 \mathrm{~kJ} \mathrm{~mol}^{-1}$. $^{2}$ In general,
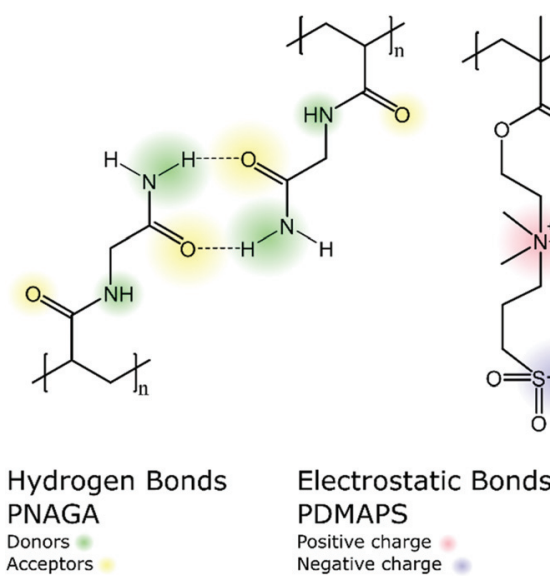

Electros

Hydrogen Bonds PNAGA Donors : Acceptors Positive charge Negative charge

Scheme 1 Schematic representation of hydrogen bonds between PNAGA side chains (left) and electrostatic bonds between zwitterionic groups in poly( $N, N^{\prime}$-dimethyl(methacryloylethyl)ammonium propanesulfonate), PDMAPS, responsible for the thermoresponsive behavior of the respective polymers.

the entropy of mixing for polymers is much lower than that for small molecules. An increase in the molecular weight decreases the entropy of mixing even further, making the solubility of the polymer more sensitive to other interactions. Therefore, a strong influence of the molecular weight on the cloud point is observed. ${ }^{5}$ For a polymer to be dissolved in a solvent, the Gibbs energy of dissolution needs to be negative. The Gibbs energy of dissolution turns positive at temperatures lower than the cloud point of a UCST polymer (eqn (1)). Thus, at the cloud point $T_{\mathrm{cp}}=\Delta H / \Delta S$ the cloud point can be affected by changing the $\Delta H$ and/or $\Delta S$. Both can be affected by copolymerization or by the presence of solutes in a polymer solution. ${ }^{15}$ Herein emerges the possibility to induce the UCST behaviour for polymers via external stimuli or additives.

$$
\Delta G_{\mathrm{m}}=\Delta H_{\mathrm{m}}-T \Delta S_{\mathrm{m}}
$$

PNIPAM is probably the most famous thermoresponsive polymer. The phase separation of the solutions of PNIPAM or other LCST polymers is driven by the association of the polymer backbone and other nonpolar groups. The phase separation is dependent on pressure and the polydispersity of the polymer. Also, when determining the cloud point, heating and cooling rates have a significant influence. It should be noted that the redissolution of the polymer is slower than the collapse of the polymer coil. The solubilisation process of PNIPAM involves re-establishing the hydrogen bonds between water and the polar groups of the polymer, along with the formation of a cage of water molecules around the nonpolar parts of the polymer, resulting in a hydrated and swollen polymer coil. Upon raising the temperature above the phase transition temperature the hydrogen bonds between the polymer and water molecules are broken, and water is released, allowing the nonpolar parts to associate along with intramolecular hydrogen bonding of the amine and carbonyl groups, ultimately collapsing the polymer coils.

As in the case of UCST polymers at temperatures lower than the cloud point, at temperatures higher than the cloud point of an LCST polymer (eqn (1)), the Gibbs energy of dissolution turns positive. The dehydration of the polymer coil leads to a change in the entropy of the system, and this overrules the enthalpy of the hydrogen bonding of the polar groups. As a result, the total energy of mixing turns positive and phase separation occurs. ${ }^{2}$

\section{Hydrogen bonding or zwitterionic UCST polymers}

In this part, we will briefly discuss polymers that exhibit UCST behavior due to hydrogen bonding or zwitterionic interactions. We also look into what kinds of factors (polymer structure, salts, molecular weight, etc.) affect the temperature dependent solution behavior of the polymers, to understand how the cloud points could be affected and tuned by additional stimuli. 
<smiles>CCC(C)CC(C)C(N)=O</smiles>

poly(acrylamide-co-acrylonitrile)

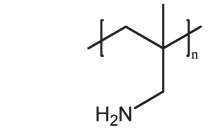

poly(methacrylamide)

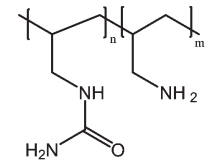

poly(allylamine-co-allylurea)

Fig. 3 Polymers showing UCST behavior in aqueous solutions. ${ }^{15,21,22,25}$

There are only a few known polymers that exhibit UCST behavior at temperatures between 0 and $100{ }^{\circ} \mathrm{C}$ (Fig. 3). PNAGA is the most studied of these and controlled polymerization using both RAFT (reversible addition-fragmentation chain-transfer polymerization) ${ }^{16,17}$ and ATRP (atom transfer radical polymerization) ${ }^{18}$ techniques have been reported. It is known that the hydrophobicity of the polymer affects the cloud point temperature. Thus the copolymerization of hydrophobic monomers, butyl acrylate or styrene, caused an increase in the cloud point. ${ }^{15}$ On the other hand, the copolymerization of NAGA with the hydrophilic $N$-acetyl-acrylamide lowered the cloud point, with increasing the molar fraction of $N$-acetyl-acrylamide. ${ }^{12}$ Similar observations were made by Mäkinen et al. while they prepared triblock copolymers of PNAGA, PNIPAM, and poly (ethylene oxide) (PEO). The authors found that the block formation of PNAGA and PNIPAM increased both the UCST and the LCST cloud point temperatures of the respective polymers. Also, the order of the blocks in the triblock copolymer had an effect on the thermoresponsiveness of the polymers. ${ }^{17}$

Copolymers of acrylamide and acrylonitrile, as well as the homopolymer of methacrylamide, have been shown to exhibit UCST behavior in aqueous solutions. In the case of the acrylamide and acrylonitrile copolymers, the cloud point was found to be dependent on the monomer ratio, as the cloud point increased with the increasing acrylonitrile content. ${ }^{15,19}$ In the case of poly(methacrylamide), the polymerization process was of importance. Free radical polymerization using AIBN as an initiator, resulting in hydrophobic end groups, yielded polymers with a cloud point at $40{ }^{\circ} \mathrm{C}(1 \mathrm{wt} \%$ solution $) .{ }^{15}$ In a previous study poly(methacrylamide) was obtained using potassium persulfate; the theta point for an aqueous solution was reported at $6{ }^{\circ} \mathrm{C}^{20}$

Ureido polymers, that is, poly(allylamine)-co-poly(allylurea) and its derivatives, have a high number of hydrogen bonding sites. In addition, the structures are resonance stabilized which may enhance the hydrogen bonding and the possibility of additional $\pi-\pi$ interactions. The cloud points increase linearly with the increasing ureido content and are lowered by an increase in the molecular weight. ${ }^{21-24}$ Glatzel et al. report on the UCST behavior of poly( $N$-acryloylaspargineamide), which has a similar structure to the ureido polymers. The cloud point of this polymer depends on both the molecular weight and concentration. ${ }^{25}$ These types of polymers are discussed in detail in a recent review by Seuring et $a .^{5}$ Worth mentioning is that thermoresponsive polymers, such as $\operatorname{poly}(N$-methacryloylglutamineamide) and its derivatives, were patented by Nagaoka et al. in $2010 .{ }^{26}$
Zwitterionic polymers, such as poly(sulfobetaine)s and poly (phosphorylcholine)s, show UCST behavior in aqueous solutions (Fig. 4). Of these two, poly(sulfobetaine)s are the most studied ones with respect to the thermoresponsive properties. The solution properties of polysulfobetaines are influenced by several factors, such as the concentration, molecular weight, presence of salts, branching of the polymer, and the spacing between the ionic units. ${ }^{27-33}$ For example, in the case of poly ( $N, N^{\prime}$-dimethyl(methacryloylethyl)ammonium propanesulfonate), PDMAPS, the molecular weight of the polymer has a strong influence on the cloud point. Short polymers under $20 \mathrm{~kg} \mathrm{~mol}^{-1}$ show no thermoresponsiveness, whereas a $50 \mathrm{~kg} \mathrm{~mol}^{-1}$ polymer has a cloud point at $11{ }^{\circ} \mathrm{C}$, and a $200 \mathrm{~kg} \mathrm{~mol}^{-1}$ at $26^{\circ} \mathrm{C}^{28}$

The presence of salt affects the solution properties of zwitterionic polymers in several ways, as salts screen the charges on the polymer. The screening of the charges affects the intraand intermolecular electrostatic attractions between the zwitterionic groups, resulting in an antipolyelectrolyte effect. ${ }^{29,32,34}$ This effect is characterized by the extension of the polymer chain and an increase in the reduced viscosity, together with a lowering of the cloud point. Hydrogen-bonded water is released to the bulk when the salt breaks bonds between the zwitterionic groups. Additionally, binding of cations to the polysulfobetaine can cause an additional positive charge on the polymer and thus result in charge repulsion. ${ }^{29}$

The cloud point is affected by the concentration of the polymer. In dilute solutions, intramolecular interactions between close by side chains or folding of the individual side

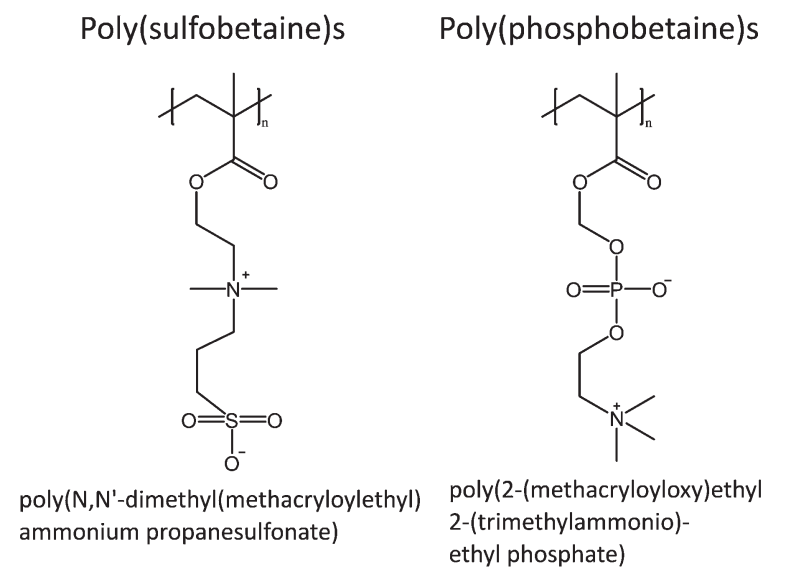

Fig. 4 Examples of zwitterionic polymers showing UCST behavior in aqueous solutions. 
chains, are favored, which would also be true for hydrogen bonding polymers. Intermolecular interactions are introduced first when the polymer concentration is increased to the overlapping concentration. In the case of poly(sulfobetaine)s in dilute solutions $(<0.8 \%)$, additional polymers act like added salts. Under these conditions, when the concentration reaches the overlapping concentration, intramolecular bonds are replaced by intermolecular bonding and the polymer redissolves. $^{29}$

Finally, it should be noted that there are several reports on poly(ethylene oxide), ${ }^{3,35,36}$ poly(vinyl methyl ether)s, ${ }^{37,38}$ polyvinylalcohols, ${ }^{39}$ and poly(hydroxymethylacrylate)s ${ }^{40}$ expressing UCST behavior. However, in most of the cases, the cloud points are either below $0{ }^{\circ} \mathrm{C}$ or close to and above $100{ }^{\circ} \mathrm{C}$.

\section{Counterion-induced UCST behaviour of polyelectrolytes}

The solution properties of polyelectrolytes are affected not only by the counterions present but also by the addition of salts; that is the introduction of more or different counterions. In this case, the nature of the salt is of importance because some salts may induce the UCST behavior in polyelectrolyte solutions. These interactions are a complex interplay affected not only by the size, polarizability, and valency of the ions, but also by their hydrophobicity.

\section{Metal cations}

Mono or divalent cations can induce UCST behavior in partially neutralized poly(acrylic acid), PAA, solutions. Flory et al. reported already in 1954 on the UCST behavior of one-third neutralized PAA in saline solution (1.245 $\mathrm{M} \mathrm{NaCl})$. In their studies, they used fractionated PAA, with molecular weights ranging from 134 to $900 \mathrm{~kg} \mathrm{~mol}^{-1}$. The phase separation temperature was found to be affected both by the polymer concentration and molecular weight. However, no clear dependence between the molecular weight of the polymer and the cloud point could be observed. In solutions with $10 \%$ neutralized PAA, it was shown that the viscosity of PAA solutions was suppressed in the presence of the divalent cations, $\mathrm{Ca}^{2+}$ or $\mathrm{Cu}^{2+}$, of which the copper ions had the most prominent effect (Fig. 5). ${ }^{41}$ The triblock copolymer PAA-Poly(propylene oxide)PAA exhibits both UCST and LCST behavior in saline solutions. The cloud point was observed to depend on the degree of neutralization and the length of the PAA blocks, which is related<smiles>CC(C)(C)CC(C(=O)[O-])C(C)(C)CC(C)(C)C</smiles>

Poly(acrylic acid)

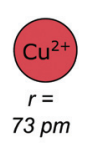

$73 \mathrm{pm}$

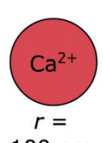

$100 \mathrm{pm} \quad 102 \mathrm{pm}$

Fig. 5 Partially neutralized poly(acrylic acid) (left) exhibits UCST behavior in the presence of various cations (right, presented with their respective effective radii). ${ }^{41}$ to the amount of hydrogen bonds between the different polymer blocks and water. ${ }^{42}$ Copolymers of methacrylic acid and dimethylaminoethyl methacrylate (DMAEMA) were recently shown to express UCST behavior in alcohols. ${ }^{43}$

\section{Halogen anions}

Biswas et al. report that poly(triphenyl-4-4-vinylbenzyl phosphonium chloride) exhibits UCST behavior in the presence of sodium salts ( $\mathrm{NaCl}, \mathrm{NaBr}$, and $\mathrm{NaI}$ ) (Fig. 6). In the absence of these salts, the polymer showed no thermoresponsiveness at all. The thermal responsiveness of the polymer was found to be dependent on the polymer concentration, the salt concentration, and the molecular weight of the polymer. For example, a $0.5 \mathrm{wt} \%$ polymer solution required the presence of $0.475 \mathrm{M}$ $\mathrm{NaCl}$ concentration. The nature of the negative ions played a significant role in inducing thermoresponsiveness of the polymer. The larger the halide ion, and thus more polarizable, the more profound was its capability to affect the solubility of the polymer. For comparison, only $20 \mathrm{mM} \mathrm{NaBr}$ and $2 \mathrm{mM}$ of $\mathrm{NaI}$ are needed to turn the polymer insoluble at room temperature. On the other hand, cyanide and thiocyanide counterions had no effect on the solubility of the polymer. Also, the presence of increasing amounts of cosolvents such as methanol, dimethylformamide, or dimethyl sulfoxide decreased the cloud points. $^{44}$

Halide ions can induce UCST behavior in branched polyethyleneimine (PEI) or partially quaternized PEI, under highly acidic $(\mathrm{pH}<0.6)$ conditions (Fig. 6). $\mathrm{HCl}, \mathrm{HBr}$, and $\mathrm{HI}$ are all capable of inducing thermoresponsiveness in PEI. However, the amount of acid needed was found to be dependent on the size, polarizability and hydrophobicity of the halide ions. $\mathrm{HBr}$ and $\mathrm{HI}$ are more efficient in inducing a cloud point than $\mathrm{HCl}$. When PEI is functionalized with 35 to $38 \%$ permanent

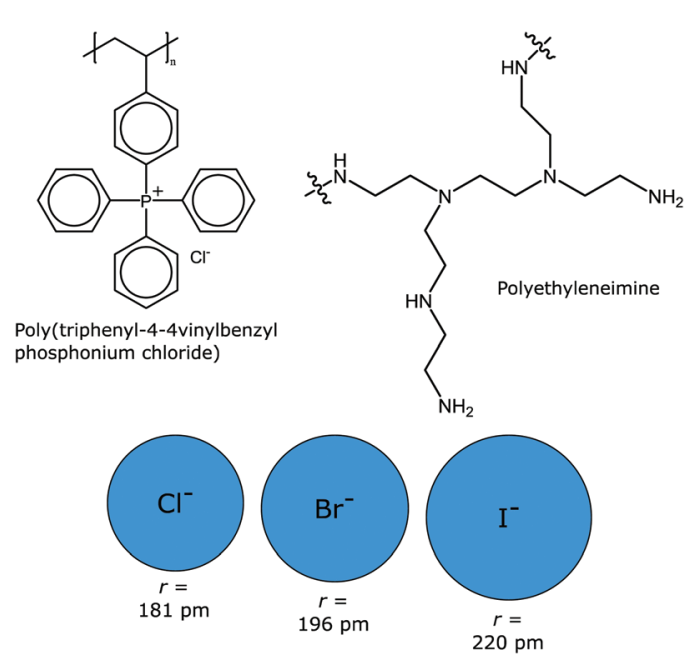

Fig. 6 Poly(triphenyl-4-4vinylbenzyl phosphonium chloride) ${ }^{44}$ and polyethyleneimine $^{45}$ (top) exhibit UCST behavior in the presence of various halide anions (below, presented with their respective effective radii). 
charges, only the iodide anions were capable of inducing a cloud point in the solution. ${ }^{45}$

\section{Hydrophobic counterions}

Aqueous solutions of polymeric ionic liquids (PILs) express thermoresponsive behavior in the presence of hydrophobic counterions. Kohno et al. have recently reviewed in detail PILs which express LCST, UCST, or both in aqueous or organic solutions. ${ }^{46}$ Tetrafluoroborate $\left(\mathrm{BF}_{4}{ }^{-}\right)$is a hydrophobic anion that can induce UCST behavior in several polymers, including PILs. The concentration of the PILs, reported by Yoshimitsu et al. (Fig. 7), had a stronger effect on the cloud point than the molecular weight of the polymers. Substituents on the imidazolium ring were found to have an effect on the polymer solubility in water in the presence of $\mathrm{BF}_{4}{ }^{-}$, hexafluoroantimonate, or bis(trifluoromethanesulfonyl)imide. However, none of these PILs showed thermoresponsive behavior in the presence of the two latter hydrophobic counterions. Polymeric ionic liquids with
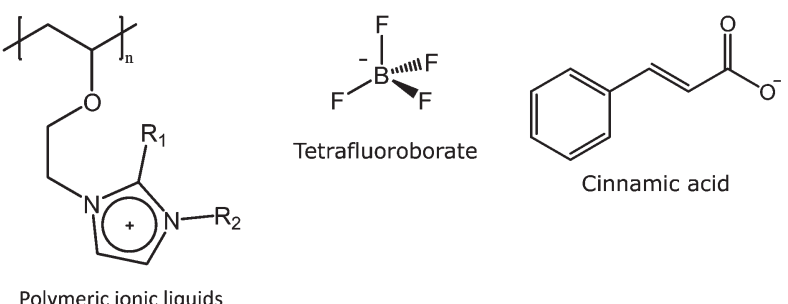

Polymeric ionic liquids

Fig. 7 Structure of polymeric ionic liquids (left, $\mathrm{R}_{1}=-\mathrm{H}$ or $-\mathrm{CH}_{3}, \mathrm{R}_{2}=$ $-\mathrm{CH}_{3},-\mathrm{C}_{2} \mathrm{H}_{5},-\mathrm{C}_{4} \mathrm{H}_{9}$, or $-\mathrm{C}_{5} \mathrm{H}_{11}$ ), which expressed UCST behavior in the presence of $\mathrm{BF}_{4}{ }^{-}$(middle). ${ }^{47} \mathrm{PEI}$ can be turned thermoresponsive both in the presence of $\mathrm{BF}_{4}{ }^{-}$and cinnamic acid (right). ${ }^{45,48}$ one or two methyl substituents on the imidazolium ring displayed thermoresponsive behavior in aqueous solutions, whereas butyl and pentyl substituted analogs were insoluble. In addition to the substituents, the counterions had a significant effect on the solubility of the polymeric ionic liquids. With chlorine as a counterion, all polymers were readily soluble in water, whereas the more hydrophobic hexafluoroantimonate or bis(trifluoromethanesulfonyl)imide turned the polymers insoluble in water. The presence of $\mathrm{NaCl}$ readily decreases the cloud points, as it disrupts the electrostatic bonding between the polymers and the hydrophobic counterions. Interestingly, these PILs show LCST behavior in organic solvents in the presence of hexafluoroantimonate, $\mathrm{SbF}_{6}{ }^{-47}$ Tetrafluoroborate can also turn PEI thermoresponsive, as is reported by Noh et al. in their studies with partially quaternized PEI. ${ }^{45}$ Cinnamic acid is another hydrophobic ion that can induce UCST behavior in PEI. The cloud point could be controlled in $\mathrm{pH} 7.0$ buffer by varying the ratio of cinnamic acid to the amino groups in the polymer. The UCST behavior of the conjugate may be used as a triggering mechanism for the release of the dye from liposomes functionalized with the conjugate. ${ }^{48}$

$\alpha$-Helical polypeptides bearing imidazolium ${ }^{49,50}$ or pyridinium $^{51}$ groups in their side chains show UCST behavior in the presence of $\mathrm{BF}_{4}{ }^{-}$in aqueous and alcoholic solutions (Fig. 8). Poly $(\gamma$-4-methylenebenzyl-L-glutamate)- $N$-butylimidazoliumchloride becomes UCST thermoresponsive in water, when the counterion is changed to $\mathrm{I}^{-}$or $\mathrm{BF}_{4}{ }^{-}$expressing $T_{\mathrm{cp}} \mathrm{s}$ at 35.6 and $69.1{ }^{\circ} \mathrm{C}$, respectively. The cloud point temperatures were observed to decrease with the addition of $\mathrm{NaCl}$ and increase with the addition of NaI or $\mathrm{NaBF}_{4} \cdot{ }^{49}$ Similar observations were made for $\operatorname{poly}(\gamma$-propyl-L-glutamate)- $N$-butylimidazolium and

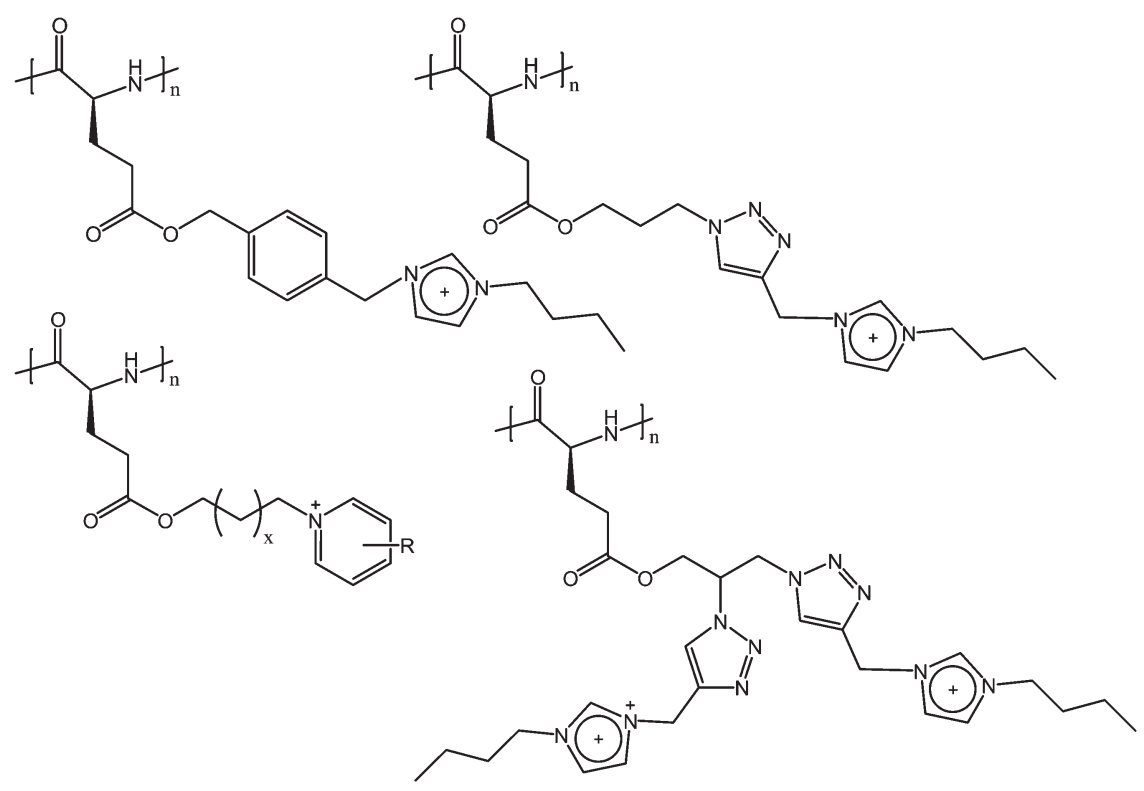

Fig. $8 \alpha$-Helical polypeptides which show UCST behavior in aqueous and alcoholic solutions; poly $(\gamma$-4-methylenebenzyl-L-glutamate)- $N$ butylimidazolium (top left), poly( $\gamma$-3-propyl-L-glutamate)- $N$-pyridinium (bottom left), poly( $\gamma$-propyl-L-glutamate)- $N$-butylimidazolium (top right), and poly $\left(\gamma\right.$-propyl-L-glutamate) bis( $N$-butylimidazolium) (bottom right). ${ }^{49-51}$ 
poly( $\gamma$-propyl-L-glutamate)bis( $N$-butylimidazolium), as polymers with $\mathrm{BF}_{4}{ }^{-}$as counter ions showed UCST behavior in methanol and aqueous solutions. In ethanol, UCST was observed with iodide as a counterion, whereas $\mathrm{BF}_{4}{ }^{-}$resulted in poor solubility of the polymers. In methanol and water, polymers with a bis( $N$-butylimidazolium $\mathrm{BF}_{4}$ ) side chain had lower $T_{\text {cp }}$ S compared with the $N$-butylimidazolium side chain. However, in ethanol with iodide as a counterion, the opposite behavior was observed. From infrared spectroscopy data the authors concluded that the polymer aggregation in ethanol was driven by hydrophobic interactions at low temperatures. At higher temperatures hydrogen bonds kept the polymers solubilized. In aqueous solutions, it is believed that the UCST behavior is driven by electrostatic interactions between the imidazole moieties and their counterions. ${ }^{50}$ The solubility of poly ( $\gamma$-3-propyl-L-glutamate)- $N$-pyridinium in water was affected by the nature of the counterions and the location of a methyl substituent on the pyridinium ring. Polymers 3 substituted with methyl groups show UCST behavior in water with $\mathrm{Cl}^{-} \mathrm{or} \mathrm{BF}_{4}{ }^{-}$ as counterions. The cloud point was observed to shift to higher temperatures with higher concentration, higher molar mass, and upon changing the counter ion from $\mathrm{Cl}^{-}$to $\mathrm{BF}_{4}{ }^{-51}$ For comparison, neutral derivatives of the polypeptides with alkyl or oligo ethylene side chains show UCST behavior only in alcoholic solvents or water/alcohol mixtures. ${ }^{52,53}$

Poly(dimethylaminoethyl methacrylate), PDMAEMA, is a $\mathrm{pH}$ and thermoresponsive polymer. It displays LCST behavior in aqueous solutions, where the cloud point is affected by the charge of the polymer, that is the $\mathrm{pH}$ of the solution. ${ }^{7,954}$ The apparent $\mathrm{p} K_{\mathrm{a}}$ of the polymer is 6.22 , thus at $\mathrm{pH}$ below 9 the polymer has a positive charge and is thus susceptible to counterions. ${ }^{54}$ The introduction of a permanent positive charge by quaternization with methyl iodide of the amine yields a strong polyelectrolyte, poly(2-methacryloyloxyethyltrimethylammonium iodide) (PMOTAI), also susceptible to chosen counterions (Fig. 9).

In the presence of bis(trifluoromethane)sulfonamide $\left(\mathrm{NTf}_{2}\right)$ PDMAEMA aggregates and a UCST cloud point appears. It should be noted that the association of $\mathrm{NTf}_{2}$ with PDMAEMA affects the $\mathrm{pH}$ of the solution. The formed tight ion pairs shield the charge of the polymer and thus increase the ability of the adjacent unit to protonate, increasing the basicity of the polymer. This minute change in the $\mathrm{pH}$ changes the solution properties enough so that the thermoresponsiveness of the polymer is lost. Due to this, studies of the UCST (and LCST) behavior of PDMAEMA have been conducted in buffered solutions. As can be expected, the cloud point is significantly affected by the amount of $\mathrm{NTf}_{2}$ and the $\mathrm{pH}$ of the solutions. In solutions with $\mathrm{pH} 7-9$, the cloud points are shifted to higher temperatures with increasing amounts of $\mathrm{NTf}_{2}$. The polymer showed no thermoresponsive behavior in solutions with $\mathrm{pH}$ above 9 or below 7 at a fixed (30 mol\%) $\mathrm{NTf}_{2}$ concentration. At low $\mathrm{pH}$, the polymers are strongly charged, and the excess of positive charges keeps the polymer chains solubilized. ${ }^{54}$

The introduction of permanent charges on PDMAEMA by a conversion to PMOTAI increases its capacity for binding ions. In this case, the presence of $\mathrm{NTf}_{2}$ leads to insoluble aggregates.

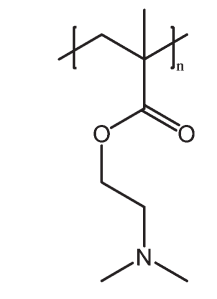

Poly(dimethylaminoethyl methacrylate)

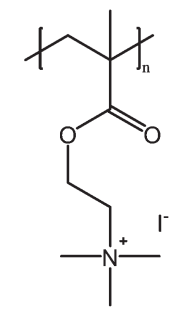

Poly(2-methacryloyloxyethyl trimethylammonium iodide)

Poly(3-methyl-1-(4- vinylbenzyl) imidazolium chloride)

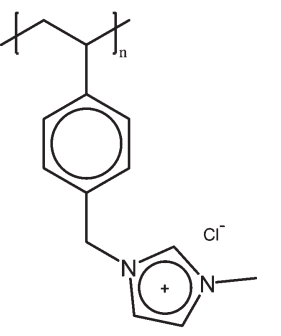

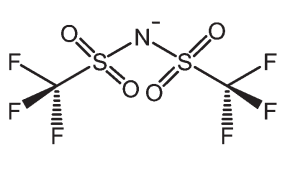

Bis(trifluoromethane) sulfonimide
Fig. 9 The polycations, poly(dimethylaminoethyl methacrylate) (PDMAEMA), poly(2-methacryloyloxyethyltrimethylammonium iodide) (PMOTAl), and poly(3-methyl-1-(4-vinylbenzyl)imidazolium chloride) can be made thermoresponsive, expressing UCST behavior in saline solutions, by the addition of hydrophobic counterions such as trifluoromethanesulfonate (OTf) or bis(trifluoromethane) sulfonamide $\left(\mathrm{NTf}_{2}\right) .{ }^{54,55}$

However, upon the addition $\mathrm{NaCl}$, a UCST cloud point emerged. Thus, with a fixed amount of $\mathrm{NTf}_{2}$ in the solution the cloud points shift to lower temperatures with increasing additions of $\mathrm{NaCl}$, up to a certain $\mathrm{NaCl}$ concentration. This is because of the competitive binding of the chloride and $\mathrm{NTf}_{2}$ ions to the polymer; as the binding reaches equilibrium, the cloud point is no more affected by the increased amount of salt. Increasing the polymer concentration decreased the cloud point temperatures at fixed PMOTAI/NTf ratios $^{55}$ Alkyl substitution of the ammonium position results in an increase of the $T_{\mathrm{cp}}$ with increasing hydrophobicity of the alkyl chain and with $\mathrm{BF}_{4}{ }^{-}$as the counterion. In $5 \% \mathrm{w} / \mathrm{v}$ solution $T_{\mathrm{cp}}$ was observed at $13{ }^{\circ} \mathrm{C}$ with methyl substituents, at $16{ }^{\circ} \mathrm{C}$ with one ethyl substituent, and at $46{ }^{\circ} \mathrm{C}$ with a butyl group..$^{56}$

Similarly to PMOTAI, the polymeric ionic liquid, poly(3methyl-1-(4-vinylbenzyl)imidazolium chloride), exhibits UCST thermoresponsiveness in the presence of $\mathrm{NTf}_{2}$ and trifluoromethanesulfonate (OTf) (Fig. 9). However, the cloud points are at much higher temperatures than those in the case of PMOTAI, due to the more hydrophobic structure of the PIL. The counter ion OTf is less hydrophobic than $\mathrm{NTf}_{2}$, thus more OTf is required to turn the PIL thermoresponsive. Similarly, as in the case of PMOTAI, the presence of $\mathrm{NaCl}$ decreases the cloud point temperatures. Interestingly, the concentration of this particular PIL does not affect the cloud point temperature, which is in contrast with the previously described PIL in the presence of $\mathrm{BF}_{4}{ }^{-55}$

\section{Multivalent anions}

UCST behavior may also be observed in PDMAEMA solutions in the presence multivalent counterions, such as hexacyanoferrate, cobaltate, or chromate (Fig. 10). ${ }^{7,57,58}$ As in the case of OTf and $\mathrm{NTf}_{2}$, the polymer has to be sufficiently charged 


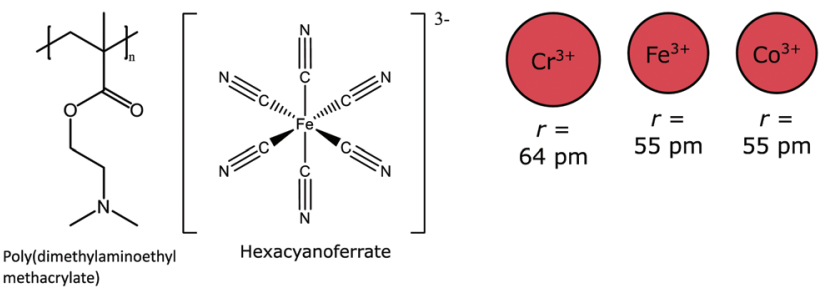

Fig. 10 PDMAEMA shows UCST thermoresponsive behavior in the presence of the multidentate anions, hexacyanochromate, -ferrate, or -cobaltate. The size of the metal ion in the complex ion affects the cloud points. ${ }^{7,57,58}$

$(\mathrm{pH}<9)$ for a UCST cloud point to be observed in the presence of hexacyano metal ions. Zhang et al. report that at pH 5 and 8 , the cloud points are shifted to higher temperatures with increasing the concentration of counterions and also, the clouding occurs at a higher temperature at $\mathrm{pH} 5$ than at $\mathrm{pH}$ 8. The authors report that the size of the metal cations in the complex ion had an effect on the cloud points. The cloud points shift to lower temperatures with the increasing atomic number of the metal ions; that is, with decreasing ionic radii of the metal ions. The charge densities of the ions change with the increasing radius, and thus the binding affinities of the metal hexacyano anions are different. ${ }^{57,58}$ By adjusting the $\mathrm{pH}$ and the amount of the counterions, it is possible to observe both the UCST and LCST behavior of the same polymer. Also, the metal hexacyano anions are susceptible to light and redox reactions. ${ }^{7,59}$

\section{Redox chemistry as a tool to affect the cloud point of UCST polymers}

Redox processes can affect the solution properties of the polymer by changing either the structure of the polymer or the oxidation state of a counterion. Both changes would affect the intermolecular interactions of the polymers, thus inducing or affecting the thermoresponsive properties of the polymers.

Recently Bertrand et al. reported on the thermoresponsive behavior of poly(TEMPO methacrylate) (PTMA) in alcoholwater solutions (Fig. 11). The cloud point temperature of the<smiles>CC(C)(C)CC(C)(C)C(=O)OC1CC(C)(C)N([O])C(C)(C)C1</smiles>

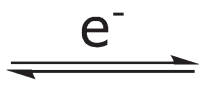

Fig. 11 The redox chemistry of poly(TEMPO methacrylate) affects the solubility and hydrophilicity of the polymer, thus affecting the cloud points in alcohol-water mixtures. ${ }^{60}$

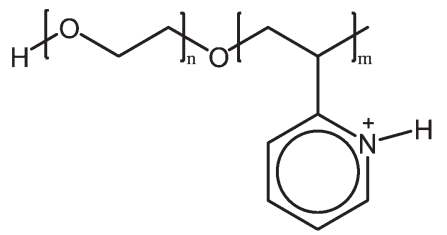<smiles>O=S(=O)([O-])OOS(=O)(=O)[O-]</smiles>

Fig. 12 Protonated poly(ethylene oxide)-b-poly(2-vinyl pyridine) exhibits UCST thermoresponsiveness in the presence of persulfate ions. ${ }^{61}$

polymer increases with increasing polymer concentration, increasing molecular weight, and decreasing polarity of the solvent. The hydrophilicity of this polymer can be changed by oxidizing the nitroxide radicals into oxoammonium cations. This oxidation can be done electrochemically or chemically with hypochlorite. The chemical oxidation is rather slow, and the authors report on oxidation times up to 7 days, whereas the electrochemical route is much faster, occurring within 5 hours. The oxoammonium anion can be reduced back to the nitroxide radical. In general, the oxidation of the nitroxide radical caused the cloud points to shift to lower temperatures, as the polymers become more hydrophilic. In the electrochemical oxidation, the solubility (and the cloud point) of the polymer can easily be cycled between soluble and insoluble forms at a given temperature, by switching the potential. ${ }^{60}$

Jia et al. report on the thermoresponsiveness and micellization of protonated poly(ethylene oxide)- $b$-poly(2-vinyl pyridine) in the presence of persulfate ions (Fig. 12). The divalent persulfate ions were capable of inducing the formation of micelles in aqueous solutions by complexing with the positively charged pyridine moieties. Upon heating the micelles are broken at $40{ }^{\circ} \mathrm{C}$ but are reformed after cooling to $25^{\circ} \mathrm{C}$, with the reformed micelles being somewhat denser than the original micelles. No noticeable change in the persulfate ion concentration was reported during repeated heating and cooling cycles, confirming that the thermoresponsiveness was due to decomplexation of the micelles, rather than the degradation of the persulfate ions. A small amount of reductant was also shown to disintegrate the micelles, which could be reformed upon addition of persulfate. Increasing the molecular weight of the poly(2-vinyl pyridine) block increased the cloud points, whereas for oligomeric blocks no cloud points were detected. ${ }^{61}$

\section{Tuning the thermoresponsiveness of polymers by light}

Light can also manipulate the thermal properties of polymers in solutions. Two known examples are polyelectrolytes with light sensitive counterions and polymers with light sensitive units in the main or side chains. Light sensitive multivalent counterions can undergo a change in the valency upon irradiation with light, thus changing the interaction between the polymer and the ion. Conformational changes in the structural units of the polymers alter the solubility of the macromolecules. 


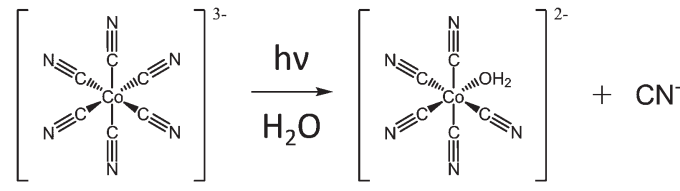

Fig. 13 Transformation of the trivalent hexacyanocobaltate anion to a divalent anion, via light-induced exchange of one cyano group with water. ${ }^{62,63}$

Plamper et al. have observed that PDMAEMA shows UCST behavior under the influence of hexacyanocobaltate counter anions. However, the charge of the anion can be altered with light. Under light irradiation one of the cyano groups of the cobaltate is exchanged with a water molecule, resulting in a divalent anion. The UCST behavior of PDMAEMA can be turned off by irradiating the samples with UV light for 10 minutes at room temperature (Fig. 13). ${ }^{62,63}$

Azobenzene is a well-known dye that undergoes trans-to-cis isomerization when irradiated with UV light $(\sim 320 \mathrm{~nm})$ at the $\pi-\pi^{*}$ absorption wavelength of the trans $\mathrm{N}=\mathrm{N}$ double bond (Fig. 14). The cis state will shift with time to the thermodynamically more favorable trans state due to thermal relaxation. The change can be accelerated thermally or by irradiation with the wavelength of the cis state (n- $\pi^{*}$, $\sim 430 \mathrm{~nm}$ ). The ratio between the trans and cis forms can be followed by UV-Vis spectroscopy, from the absorbances of the trans $\pi-\pi^{*}$ and cis $\mathrm{n}-\pi^{*}$ transitions. Upon the trans-to-cis isomerization, the dipole moment of the azobenzene unit increases from 0.5 to $3.1 \mathrm{D}$. This changes the solution properties of the molecule. ${ }^{64}$

Wiktorowicz et al. incorporated azobenzene units in the main chain of poly(azocalix-4-arene)s and poly(azidobenzo-18crown-6-ether)s (Fig. 15). Poly(azocalix-4-arene)s display UCST behavior in methanol, ethanol, $n$-propanol, and 2-propanol.

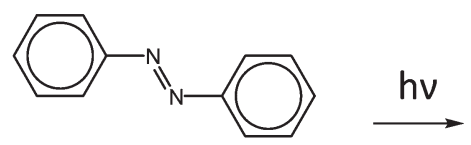

trans-azobenzene

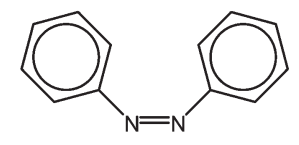

cis-azobenzene
Fig. 14 The photoisomerization of azobenzene.

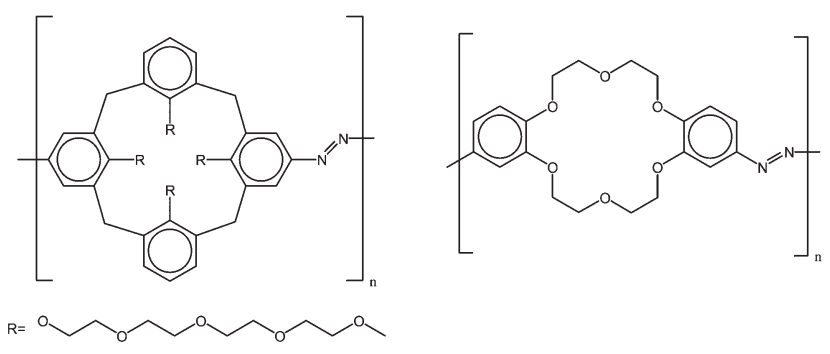

Fig. 15 Poly(azocalix-4-arene)s $s^{65}$ and poly(azidobenzo-18-crown-6ether)s ${ }^{66}$ exhibit photo tunable UCST phase transition in alcohols.
The cloud point temperatures not only increase with the increasing molecular weight or concentration but also with decreasing polarity of the solvent, the least polar 2-propanol giving the highest cloud points. The authors studied the effect of the photoisomerization in ethanol and irradiated the polymers with UV light at $365 \mathrm{~nm}$ at room temperature, a temperature above the cloud point of the polymer. The irradiation caused a proportional decrease in the cloud point with increasing the cis content in the polymer. The drop in the cloud point indicates a better solubility of the polymer upon irradiation and photoisomerization. ${ }^{65} \mathrm{~A}$ similar behavior is reported for poly(azidobenzo-18-crown-6-ether)s, which exhibit UCST thermoresponsiveness in alcohols. As with the poly(azocalix-4arene)s the cloud point of poly(azidobenzo-18-crown-6-ether)s increased with the increasing molecular weight of the polymer or with the increasing polymer concentration. Irradiation of the polymers shifted the cloud point from 45 to $15^{\circ} \mathrm{C}$, when increasing the cis content from $35 \%$ to $65 \%$. Complexation of the crown ethers with barium increased the cloud point temperatures but also diminished the shift of the cloud point induced by irradiation, as the complexed barium ions acted as cross-linkers in the polymer solution. ${ }^{66}$

Azobenzenes as side groups in UCST polymers also have an effect on the cloud point of the polymers. Zhang et al. prepared a series of poly(methyl methacrylate) copolymers with repeating units containing azobenzene (6-8\%) and isopropylamine or ethanolamine (6-8\%). These copolymers show UCST behavior in ethanol-water mixtures (Fig. 16). Upon irradiation, the cloud points shift to lower temperatures due to the increased polarity of the cis azobenzene group. The change in the cloud point temperature caused by the photoisomerization was observed to depend almost linearly on increasing the water content. In pure ethanol, no change in the cloud point was observed, but in $60 \%$ ethanol the cloud points changed 6 degrees during the irradiation. ${ }^{67}$

Poly( $N$-isopropyl acrylamides $)$ with 9 to $30 \%$ azobenzene containing repeating units show a UCST phase transition in an ionic liquid (1-ethyl-3-methylimidazolium bis(trifluoromethane sulfone)amide) (Fig. 17). Upon irradiation and photoisomerization of the azobenzene groups, the cloud point

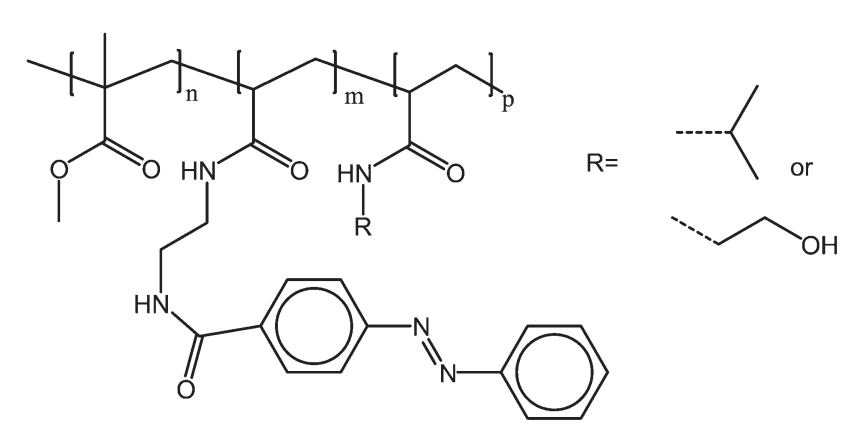

Fig. 16 Poly(methyl methacrylate) copolymers with azobenzene $(6-8 \%)$ and isopropylamine or ethanolamine $(6-8 \%)$ as side groups, change their cloud point temperatures upon the photoisomerization of the azobenzene groups. ${ }^{67}$ 


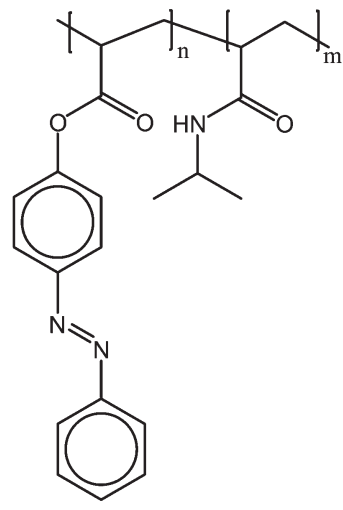

Fig. 17 The classical LCST polymer PNIPAM exhibits a phototunable UCST transition in ionic liquids when copolymerized with an azobenzene containing a comonomer. ${ }^{68}$

shifted from 50.9 to $7.9^{\circ} \mathrm{C}$. The transition broadened with the increasing amount of azobenzene containing comonomers. While the azobenzenes are in the cis-form, the polymer is readily soluble at ambient temperatures. Illuminating the polymers with light in the visible spectra turns the polymer insoluble, as the azobenzenes relax back to the planar and less polar trans form. ${ }^{68}$

\section{Influencing the UCST phase transition with $\mathrm{pH}$}

Protonation and deprotonation of functional groups is a way to affect the hydrogen bonding and electrostatic interactions of polymers. As has been shown above, both hydrogen bonds and electrostatic interactions between polymers are important in polymer solutions with a UCST transition. The interplay between the two forces is delicate, as electrostatic interactions can overrule the weaker hydrogen bonds, resulting in a loss of the thermoresponsiveness of the polymers.

Higashi et al. prepared a series of poly( $N$-acryloyl amino acid)s of the amino acids such as glycine, alanine, phenylalanine, and valine (Fig. 18). The hydrogen bonding capabilities of the polymers can be affected by protonation of the carboxylic acid. The polymers show thermoresponsive behavior in<smiles>[R]C(NC(=O)C(CC(C)C)CC(C)(C)C)C(=O)O</smiles>

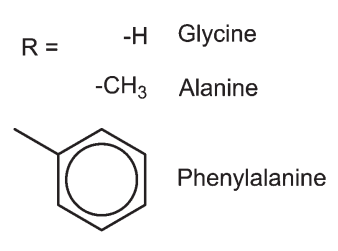<smiles>CCC(C)C(=O)OCC(N)C(=O)O</smiles>

Fig. $18 \mathrm{pH}$ sensitive poly $\left(N\right.$-acryloyl amino acid)s (left ${ }^{69}$ and the zwitterionic poly(L-serinyl acrylate) (right) ${ }^{70}$ that show $\mathrm{pH}$ dependent thermoresponsiveness in aqueous solutions. solutions with $\mathrm{pH}$ under 3 . In contrast, the methyl esters of the polymers show LCST behavior. The solubility of the polymers is also affected by the substituents in the side groups, methyl and phenyl groups (alanine and phenylalanine) yielding in less soluble polymers. The valine-derived polymer with an isopropyl side group was not water soluble at all. The phase transition of the phenylalanine-containing polymer was less well defined than that in the case of the glycine and alanine derived polymers. ${ }^{69}$

Another example of a $\mathrm{pH}$ dependent UCST polymer is poly (L-serinyl acrylate) (Fig. 18), which is thermoresponsive only at low $\mathrm{pH}$ (2-3.5), where the polymer exists in its zwitterionic form. As is typical for zwitterionic UCST polymers, the cloud point shifts to higher temperatures upon increasing the molecular weight of the polymer or the concentration of the solution. The addition of salt had an opposite effect, lowering the cloud point. In the $\mathrm{pH}$ range of 2 to 3.5 , the cloud point temperature increased with increasing $\mathrm{pH}$ until a maximum was reached at $\mathrm{pH} 2.8$, after which the cloud point temperatures started to decrease. ${ }^{70}$

Poly(dimethyl 3,3'-(((1-(2-hydroxy-3-(methacryloyloxy) propyl)-1H-1,2,3-triazol-4-yl)methyl)azanediyl) dipropanoate) and it derivatives (Fig. 19) show both UCST and LCST behavior in phosphate buffered saline solutions (PBS), with $\mathrm{pH}$ from 4.7 to 7.8. Although all of these polymers showed both UCST and LCST behaviors in PBS, only the carboxylic acid derivative showed thermoresponsive behavior in water. In PBS, the LCST cloud points of the polymers shifted to higher temperatures with increasing $\mathrm{pH}$ and were between 40 and $60^{\circ} \mathrm{C}$. The UCST cloud points, observed between 79 and $88^{\circ} \mathrm{C}$, are less affected by the $\mathrm{pH}$ of the solution. The minute effect of $\mathrm{pH}$ on the UCST cloud points is reasonable because the phase mixing

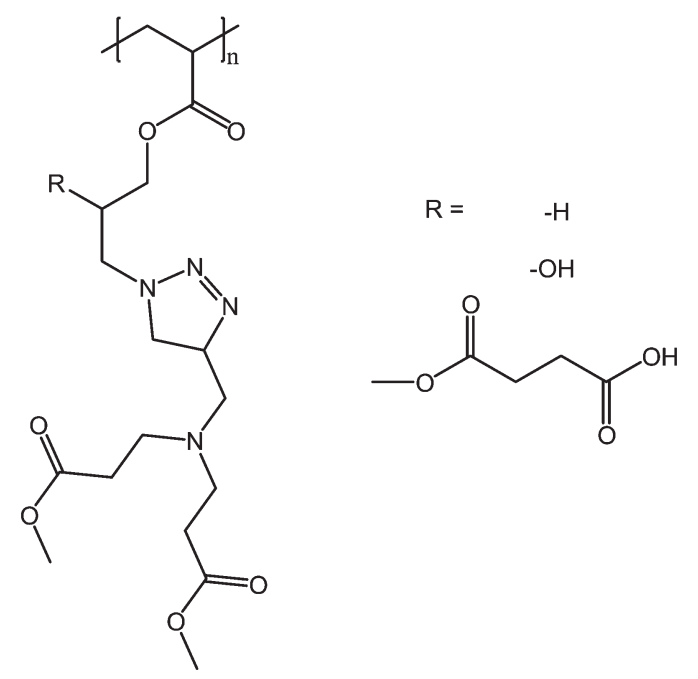

Fig. 19 Poly(dimethyl 3,3'-(((1-(2-hydroxy-3-(methacryloyloxy)propyl)$1 H$-1,2,3-triazol-4-yl)methyl)azanediyl) dipropanoate) and it derivatives show both the UCST and LCST behavior in buffered solutions, with $\mathrm{pH}$ ranging from 4.7 to $7.8 .^{71}$ 
occurs at a very high temperature where the polymers are highly mobile, and both hydrogen and electrostatic bonds are readily broken. ${ }^{71}$

Zhang et al. have demonstrated how the addition of pH sensitive comonomers in a UCST polymer can be used to adjust or change the cloud point of the polymer. Copolymers of acrylamide and acrylonitrile showed a cloud point at around $42^{\circ} \mathrm{C}$, which is unaffected by a change in the $\mathrm{pH}$ from 3 to $10 . \mathrm{pH}$ sensitivity was then created by adding comonomers carrying either carboxylic or pyridine side groups to the structures. As a next step, the authors synthesized a triblock copolymer with a hydrophobic segment of poly(dimethyl acrylamide) as a central block. The triblock copolymer had hydrophilic copolymers at both ends, comprising of acrylamide, acrylonitrile, and vinyl-4-pyridine. The triblock copolymers formed stable micelles at the cloud point in solutions with $\mathrm{pH}$ ranging from 4.75 to 7.0. At a pH lower than 4.75 , the micelles disintegrated. These thermoresponsive micelles can thus release their cargo by a change in the $\mathrm{pH}$ (or temperature, although the authors did not discuss this aspect) of the solution. ${ }^{72}$

Ureido polymers discussed already above have also been turned pH-responsive by succinylation or carboxylation (Fig. 20). These derivatives contain both amino and carboxyl groups, which make the polymers $\mathrm{pH}$ responsive. In solutions where the amino or carboxylate groups are charged, the presence of salt decreases the cloud points. The carboxylate groups are more affected by the salt than the ammonium cations, due to the difference in their capabilities of forming hydrogen bonds and affinities for counterions. ${ }^{21,22}$

Meiswinkel et al. reported that copolymers of $N$-vinylimidazole and 1-vinyl-2-(hydroxymethyl)imidazole exhibit UCST behavior in aqueous solutions, due to the hydrogen bonds between the -OH group and the basic nitrogen of the imidazole (Fig. 21). An increase in the 1-vinyl-2-(hydroxymethyl)imidazole content shifted the cloud points to higher temperatures, as it resulted in the formation of more hydrogen bonds. The cloud points show $\mathrm{pH}$ dependency since the amines can be protonated at low $\mathrm{pH}$. Due to the high charge of the polymer (vinylimidazole: 1-vinyl-2-(hydroxymethyl)imidazole, $1: 1.2$ ), no thermoresponsiveness was observed at $\mathrm{pH}$ 4. At $\mathrm{pH} 7$, the cloud point occurred at $33^{\circ} \mathrm{C}$ and in solutions with pH 11 at $49^{\circ} \mathrm{C}$. The salt also had an effect on the cloud

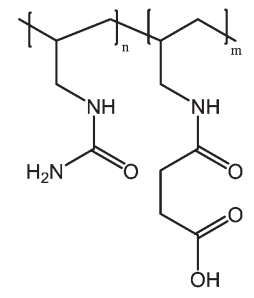

Succinylated poly(allylamine-co-allylurea)

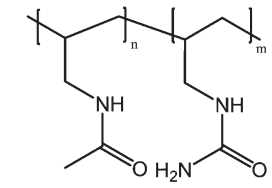

Carboxylated poly(allylamine-co-allylurea)
Fig. 20 Ureido polymer derivatives containing amino and carboxyl groups show a $\mathrm{pH}$ and salt-dependent thermoresponsive behavior. ${ }^{21,22}$

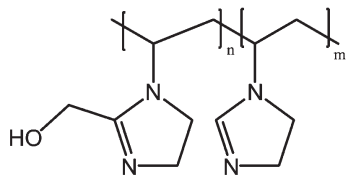

Fig. 21 The cloud point of poly(1-vinyl-2-[hydroxymethyl]imidazoleco-vinylimidazole) is affected by the monomer ratio and the $\mathrm{pH}$ of the solution, which both affect the overall amount of hydrogen bonds between the polymers. ${ }^{73}$

point of the copolymers, as it lowered the cloud point of a $1: 1$ copolymer from 41 to $26^{\circ} \mathrm{C}$ in solutions with $\mathrm{pH} 7 .^{73}$

\section{Conclusions}

In this mini-review, we have collected examples of how stimuliresponsive polymers, which undergo a UCST phase transition, are affected by stimuli, such as ions, $\mathrm{pH}$, light, and electricity. These stimuli change the polarity of the polymers and thus their capability of engaging in hydrogen or electrostatic interactions, which are the key aspects in the solution properties of UCST polymers. Although hydrophobic interactions are of importance, their influence on the thermoresponsive behavior of polymers in aqueous solutions is not as prominent as in the case of LCST polymers. Due to the intense secondary bonding between the repeating units, the cloud points of the thermoresponsive materials are greatly influenced by the molecular mass of the polymer, the polymer concentration in the solution, the presence of ions, and last but not least, the temperature of the solution. Together, all of these factors provide us with a multitude of tools to tailor the solution properties of thermoresponsive materials to meet the specific needs of any application.

For several future applications, the UCST phenomenon is worth further studies. The types of polymers discussed in this review may be expected to find numerous uses, e.g. in drug delivery systems where solid carriers dissolve upon heating. Several UCST polymers as those based on amino acids, as well as zwitterionic polymers are biocompatible. In diagnostic or sensor devices one should be able to utilize the phase separation/mixing triggered by a certain analyte. Furthermore, UCST polymers are excellent candidates as carriers for several types of catalysts.

\section{Acknowledgements}

We are grateful for the financial support from the Academy of Finland (grant 278720).

\section{References}

1 M. A. C. Stuart, W. T. S. Huck, J. Genzer, M. Müller, C. Ober, M. Stamm, G. B. Sukhorukov, I. Szleifer, 
V. V. Tsukruk, M. Urban, F. Winnik, S. Zauscher, I. Luzinov and S. Minko, Nat. Mater., 2010, 9, 101-113.

2 V. Aseyev, H. Tenhu and F. M. Winnik, in Self Organized Nanostructures of Amphiphilic Block Copolymers II, ed. A. H. E. Müller and O. Borisov, Springer, Berlin Heidelberg, 2011, pp. 29-89.

3 Y. C. Bae, S. M. Lambert, D. S. Soane and J. M. Prausnitz, Macromolecules, 1991, 24, 4403-4407.

4 A. Halperin, M. Kröger and F. M. Winnik, Angew. Chem., Int. Ed., 2015, 54, 15342-15367.

5 J. Seuring and S. Agarwal, Macromol. Rapid Commun., 2012, 33, 1898-1920.

6 Q. Zhang and R. Hoogenboom, Prog. Polym. Sci., 2015, 48, 122-142.

7 F. A. Plamper, A. Schmalz and A. H. E. Müller, J. Am. Chem. Soc., 2007, 129, 14538-14539.

8 F. A. Plamper, A. A. Steinschulte, C. H. Hofmann, N. Drude, O. Mergel, C. Herbert, M. Erberich, B. Schulte, R. Winter and W. Richtering, Macromolecules, 2012, 8021-8026.

9 J. Niskanen, C. Wu, M. Ostrowski, G. G. Fuller, S. Hietala and H. Tenhu, Macromolecules, 2013, 46, 2331-2340.

10 Y. Maeda, M. Ide and H. Kitano, J. Mol. Liq., 1999, 80, 149163.

11 H. Kitano, Polym. J., 2016, 48, 15-24.

12 J. Seuring and S. Agarwal, Macromol. Chem. Phys., 2010, 211, 2109-2117.

13 J. Seuring, F. M. Bayer, K. Huber and S. Agarwal, Macromolecules, 2012, 45, 374-384.

14 J. Seuring and S. Agarwal, ACS Macro Lett., 2013, 2, 597-600.

15 J. Seuring and S. Agarwal, Macromolecules, 2012, 45, 39103918.

16 F. Liu, J. Seuring and S. Agarwal, J. Polym. Sci., Part A: Polym. Chem., 2012, 50, 4920-4928.

17 L. Mäkinen, D. Varadharajan, H. Tenhu and S. Hietala, Macromolecules, 2016, 49, 986-993.

18 F. Liu, J. Seuring and S. Agarwal, Polym. Chem., 2013, 4, 3123-3131.

19 F. Käfer, F. Liu, U. Stahlschmidt, V. Jérôme, R. Freitag, M. Karg and S. Agarwal, Langmuir, 2015, 31, 8940-8946.

20 A. Silberberg, J. Eliassaf and A. Katchalsky, J. Polym. Sci., 1957, 23, 259-284.

21 N. Shimada, H. Ino, K. Maie, M. Nakayama, A. Kano and A. Maruyama, Biomacromolecules, 2011, 12, 3418-3422.

22 N. Shimada, M. Nakayama, A. Kano and A. Maruyama, Biomacromolecules, 2013, 14, 1452-1457.

23 A. Fujihara, N. Shimada, A. Maruyama, K. Ishihara, K. Nakai and S. Yusa, Soft Matter, 2015, 11, 5204-5213.

24 A. Fujihara, K. Itsuki, N. Shimada, A. Maruyama, N. Sagawa, T. Shikata and S.-I. Yusa, J. Polym. Sci., Part A: Polym. Chem., 2016, 54, 2845-2854.

25 S. Glatzel, A. Laschewsky and J.-F. Lutz, Macromolecules, 2011, 44, 413-415.

26 H. Nagaoka, O. Noriyuki and E. Masaru, United States Patent, US7847047B2, 2010.

27 P. Mary, D. D. Bendejacq, M.-P. Labeau and P. Dupuis, J. Phys. Chem. B, 2007, 111, 7767-7777.
28 H. Willcock, A. Lu, C. F. Hansell, E. Chapman, I. R. Collins and R. K. O'Reilly, Polym. Chem., 2014, 5, 1023-1030.

29 D. N. Schulz, D. G. Peiffer, P. K. Agarwal, J. Larabee, J. J. Kaladas, L. Soni, B. Handwerker and R. T. Garner, Polymer, 1986, 27, 1734-1742.

30 Y.-J. Shih and Y. Chang, Langmuir, 2010, 26, 17286-17294.

31 M. B. Huglin and M. A. Radwan, Polym. Int., 1991, 26, 97-104.

32 M. B. Huglin and M. A. Radwan, Makromol. Chem., 1991, 192, 2433-2445.

33 W.-F. Lee and C.-C. Tsai, Polymer, 1994, 35, 2210-2217.

34 W.-F. Lee and C.-C. Tsai, Polymer, 1995, 36, 357-364.

35 S. Saeki, N. Kuwahara, M. Nakata and M. Kaneko, Polymer, 1976, 17, 685-689.

36 E. E. Dormidontova, Macromolecules, 2002, 35, 987-1001.

37 K. Van Durme, G. Van Assche, E. Nies and B. Van Mele, J. Phys. Chem. B, 2007, 111, 1288-1295.

38 G. Van Assche, B. Van Mele, T. Li and E. Nies, Macromolecules, 2011, 44, 993-998.

39 T. Shiomi, K. Imai, C. Watanabe and M. Miya, J. Polym. Sci., Polym. Phys. Ed., 1984, 22, 1305-1312.

40 R. Longenecker, T. Mu, M. Hanna, N. A. D. Burke and H. D. H. Stöver, Macromolecules, 2011, 44, 8962-8971.

41 P. J. Flory and J. E. Osterheld, J. Phys. Chem., 1954, 58, 653661.

42 C. Pottier, G. Morandi, C. Rihouey, V. Dulong, L. Picton and D. Le Cerf, J. Polym. Sci., Part B: Polym. Phys., 2016, 54, 1507-1514.

43 Q. Zhang and R. Hoogenboom, Chem. Commun., 2014, 51, 70-73.

44 Y. Biswas, T. Maji, M. Dule and T. K. Mandal, Polym. Chem., 2016, 7, 867-877.

45 M. Noh, S. Kang, Y. Mok, S. J. Choi, J. Park, J. Kingma, J.-H. Seo and Y. Lee, Chem. Commun., 2015, 52, 509-512.

46 Y. Kohno, S. Saita, Y. Men, J. Yuan and H. Ohno, Polym. Chem., 2015, 6, 2163-2178.

47 H. Yoshimitsu, A. Kanazawa, S. Kanaoka and S. Aoshima, Macromolecules, 2012, 45, 9427-9434.

48 H. Guo and J.-C. Kim, Int. J. Pharm., 2015, 494, 172-179.

49 Y. Deng, Y. Xu, X. Wang, Q. Yuan, Y. Ling and H. Tang, Macromol. Rapid Commun., 2015, 36, 453-458.

50 C. Ge, S. Liu, C. Liang, Y. Ling and H. Tang, Polym. Chem., 2016, 7, 5978-5987.

51 Y. Wu, X. Wang, Y. Ling and H. Tang, RSC Adv., 2015, 5, 40772-40778.

52 W. Liu, M. Zhu, J. Xiao, Y. Ling and H. Tang, J. Polym. Sci., Part A: Polym. Chem., 2016, 54, 3425-3435.

53 M. Zhu, W. Liu, J. Xiao, Y. Ling and H. Tang, J. Polym. Sci., Part A: Polym. Chem., 2016, 54, 3444-3453.

54 E. Karjalainen, V. Aseyev and H. Tenhu, Macromolecules, 2014, 47, 2103-2111.

55 E. Karjalainen, V. Aseyev and H. Tenhu, Macromolecules, 2014, 47, 7581-7587.

56 X. Cao and Z. An, Macromol. Rapid Commun., 2015, 36, 2107-2110.

57 Q. Zhang, J.-D. Hong and R. Hoogenboom, Polym. Chem., 2013, 4, 4322-4325. 
58 Q. Zhang, F. Tosi, S. Üğdüler, S. Maji and R. Hoogenboom, Macromol. Rapid Commun., 2015, 36, 633-639.

59 F. A. Plamper, L. Murtomäki, A. Walther, K. Kontturi and H. Tenhu, Macromolecules, 2009, 42, 7254-7257.

60 O. Bertrand, A. Vlad, R. Hoogenboom and J.-F. Gohy, Polym. Chem., 2016, 7, 1088-1095.

61 X. Jia, D. Chen and M. Jiang, Chem. Commun., 2006, 17361738.

62 F. A. Plamper, J. R. McKee, A. Laukkanen, A. Nykänen, A. Walther, J. Ruokolainen, V. Aseyev and H. Tenhu, Soft Matter, 2009, 5, 1812-1821.

63 F. A. Plamper, A. Walther, A. H. E. Müller and M. Ballauff, Nano Lett., 2007, 7, 167-171.

64 G. S. Kumar and D. C. Neckers, Chem. Rev., 1989, 89, 19151925.

65 S. Wiktorowicz, H. Tenhu and V. Aseyev, Macromolecules, 2013, 46, 6209-6216.
66 S. Wiktorowicz, R. Duchêne, H. Tenhu and V. Aseyev, Polym. Chem., 2014, 5, 4693-4700.

67 Q. Zhang, P. Schattling, P. Theato and R. Hoogenboom, Eur. Polym. J, 2015, 62, 435-441.

68 T. Ueki, Y. Nakamura, A. Yamaguchi, K. Niitsuma, T. P. Lodge and M. Watanabe, Macromolecules, 2011, 44, 6908-6914.

69 N. Higashi, R. Sonoda and T. Koga, RSC Adv., 2015, 5, 67652-67657.

70 T. Maji, S. Banerjee, Y. Biswas and T. K. Mandal, Macromolecules, 2015, 48, 4957-4966.

71 X. Cai, L. Zhong, Y. Su, S. Lin and X. He, Polym. Chem., 2015, 6, 3875-3884.

72 H. Zhang, S. Guo, W. Fan and Y. Zhao, Macromolecules, 2016, 49, 1424-1433.

73 G. Meiswinkel and H. Ritter, Macromol. Rapid Commun., 2013, 34, 1026-1031. 